\title{
The onset of seasonal quiescence in the female Bennett's wallaby (Macropus rufogriseus rufogriseus)
}

\author{
J. D. Curlewis, A. S. White and A. S. I. Loudon \\ M.R.C./A.F.R.C. Comparative Physiology Research Group, The Institute of Zoology, \\ The Zoological Society of London, Regent's Park, London NWI 4RY, U.K.
}

\begin{abstract}
Summary. The breeding season of the non-lactating Bennett's wallaby terminates when animals enter the state of seasonal quiescence. To examine this transition, pouch young were removed from females at intervals which were 3,4 or 8 weeks $(6,11$ and 8 animals respectively) after the winter solstice. Within 48 days, 3, 1 and 1 females gave birth respectively, indicating that these animals were not in seasonal quiescence when pouch young were removed. Those animals which did not give birth were either in seasonal quiescence or had undergone a non-pregnant cycle. To differentiate between the 2 possibilities, techniques which would ensure the detection of pregnant and nonpregnant cycles were assessed in 8 females during the breeding season. As has been previously reported for the wallaby, changes in peripheral progesterone concentrations and the vaginal smear occurred during pregnant and non-pregnant reproductive cycles. In addition, mating was detected by marking the male with a mixture of coloured crayon and paraffin wax. It was concluded that reproductive cycles in female wallabies could be monitored by collecting blood samples 2 times each week for progesterone determination and daily examination of females for mating marks. These techniques were then used to study the onset of seasonal quiescence in 9 females. All animals continued to show reproductive cycles after the winter solstice and it was not until 10 weeks after the winter solstice that all animals were in seasonal quiescence. This represents an increase in the duration of the breeding season over that previously reported for this species.
\end{abstract}

\section{Introduction}

The Bennett's wallaby (Macropus rufogriseus rufogriseus) and tammar wallaby (Macropus eugenii) are species of macropodid marsupial in which there is an 11 -month period of embryonic diapause (Berger, 1966; Merchant \& Calaby, 1981). The distribution of births in each species is highly seasonal with most young born 1-2 and 2-6 months after the summer solstice for the tammar and Bennett's wallabies respectively (tammar wallaby: Andrewartha \& Barker, 1969; Bennett's wallaby: Catt, 1977; Fleming et al., 1983). After conception at the post-partum oestrus, the resultant blastocyst and corpus luteum remain in quiescence until the breeding season of the following year. During the breeding season, removal of the pouch young results in reactivation of the quiescent corpus luteum and blastocyst with birth about 27 days later (lactational quiescence; TyndaleBiscoe et al., 1974; Merchant, 1979; Merchant \& Calaby, 1981). After the breeding season, cessation of lactation by removal of pouch young or natural weaning is not followed by immediate reactivation of the corpus luteum and blastocyst but quiescence is maintained until the next breeding season (seasonal quiescence; Berger \& Sharman, 1969; Tyndale-Biscoe et al., 1974; Merchant \& Calaby, 1981).

The timing of the termination of seasonal quiescence at the beginning of the breeding season has been well documented for both species, probably, at least in part, because the indicator of that 
transition (i.e. the birth of pouch young) is readily observed. In contrast, the transition from lactational to seasonal quiescence at the end of the breeding season is not readily observed because in free-ranging populations the transition is normally masked by lactation. To determine when animals enter seasonal quiescence, it is necessary to hold animals in captivity, remove pouch young and then monitor subsequent reproductive activity. Detailed information of this type has not been published for the tammar but in a small study of Bennett's wallaby, Merchant \& Calaby (1981) reported that the transition from lactational to seasonal quiescence occurred over the period from 1 month before to about 1 week after the winter solstice. In contrast, we have observed a later onset of seasonal quiescence (present study, Exp. 1) and so subsequent experiments were undertaken to investigate this event further. A detailed study of the reproductive biology of the Bennett's wallaby was also undertaken so that reliable indicators of pregnant and non-pregnant cycles could be identified (Exp. 2). These techniques were then used in a detailed investigation of the onset of seasonal quiescence (Exp. 3).

\section{Materials and Methods}

\section{Animals and experiments}

Female Bennett's wallabies with pouch young were obtained from Whipsnade Park, Bedfordshire, and were housed in the presence of a male and under the husbandry conditions described previously (Curlewis et al., 1986). The origin of the population at Whipsnade has been described elsewhere (Fleming et al., 1983).

Collection of blood samples. In Exps 2 and 3, blood was obtained by venepuncture of the lateral tail vein and was kept on ice until centrifugation. Plasma was separated and stored at $-20^{\circ} \mathrm{C}$ until assay.

Experiment 1 . On 14 and 25 January 1985 and 16 February 1984, pouch young were removed from groups of 6,11 and 8 females respectively and, from Days 28 to 48 after removal, pouches were inspected each week for newborn pouch young.

Experiment 2. Pouch young were removed from 8 animals on 23 October (Day 0 ) and blood was collected at daily intervals from Days -2 to 9 , then 3 times a week to Day 26 and on Days 27, 28, 29, 30, 33 and 34. Vaginal smears were taken twice weekly from Days 5 to 19 and then daily until Day 33. Interpretation of vaginal smears taken from the Bennett's wallaby has been described by Merchant \& Calaby (1981). The ventral lower abdomen of the male housed with the females was marked from Day 26 onwards with a mixture of coloured ram harness crayon melted in paraffin wax. This procedure was repeated every 3 or 4 days. Over the period from Days 26 to 40 , females were checked daily for a coloured mating mark located on the rump or the base of the tail, a mating plug or the presence of a neonate in the pouch.

Experiment 3. Nine females were studied from the beginning of December 1985 until April or June 1986. Pouch young were removed on 20 December, 5 February and 6 March. To monitor reproductive activity, blood samples were collected twice weekly for plasma progesterone determination and pouches were inspected regularly for new born pouch young. In addition males were marked with coloured paraffin wax as described above and females were inspected regularly for a mating mark.

\section{Progesterone assay}

Extraction. Duplicate $200 \mu \mathrm{l}$ samples of plasma were extracted with 10 volumes of freshly redistilled $n$-hexane by mixing on a multi-tube vortex mixer (Alpha Laboratories, Eastleigh, Hants) for $15 \mathrm{~min}$. Samples were then snapfrozen and the solvent decanted into glass tubes for evaporation under nitrogen at $45^{\circ} \mathrm{C}$. The dried extract was allowed to reconstitute overnight in $1.0 \mathrm{ml}$ assay buffer, from which a $200 \mu \mathrm{l}$ sample was taken for assay. The efficiency of the extraction procedure was monitored in each assay by determining the recovery of $\left[{ }^{3} \mathrm{H}\right]$ progesterone equilibrated with endogenous plasma progesterone. Mean recovery over 14 assays was $73 \pm 4.8 \%$ (s.e.m.). Plasma concentrations were not corrected for these losses.

Radioimmunoassay. Progesterone was measured by radioimmunoassay using antiserum S1508/10 supplied by $\mathrm{Dr}$ J. Foulkes, M.A.F.F., Cattle Breeding Centre, Shinfield, Reading, U.K. It was raised in sheep against progesterone-1l $\alpha$-hemisuccinate conjugated to ovalbumin. The gamma-globulin fraction was obtained by precipitation with ammonium sulphate and absorbed free of ovalbumin antibodies before storage at $-20^{\circ} \mathrm{C} .{ }^{125} \mathrm{I}$ labelled progesterone was supplied by N.E.T.R.I.A. (St Bartholomew's Hospital, London, U.K.) and was prepared as described by Webley \& Edwards (1985). Progesterone standard (Sigma Chemical Co., St Louis, MO, U.S.A.) was 
added at concentrations of $0 \cdot 8-50 \mathrm{pg} /$ tube. Free and bound ${ }^{125}$ I-labelled progesterone were separated by a second antiserum method using donkey anti-sheep serum.

All dilutions were made in $0.1 \mathrm{M}$-sodium phosphate buffer containing $10 \%$ gelatine $(\mathrm{w} / \mathrm{v})$, $\mathrm{pH} 7 \cdot 0$. Samples and standards were incubated for $3 \mathrm{~h}$ at room temperature with antiserum $\mathrm{S1508/10}$ (final dilution 1 in 96000 ) and ${ }^{125}$ I-labelled progesterone (10000 c.p.m./tube). Donkey anti-sheep serum $(100 \mu \mathrm{l}$ at 1 in 40 dilution) and normal sheep serum ( $100 \mu \mathrm{l}$ at 1 in 800 dilution) were then added and the incubation continued overnight at $4^{\circ} \mathrm{C}$. After the addition of $1.0 \mathrm{ml} 0.9 \%(\mathrm{w} / \mathrm{v}) \mathrm{NaCl}$ containing $0.2 \%$ Triton $\times 100$, the bound and free hormone were separated by centrifugation and the radioactivity of the precipitate was measured in a gamma counter.

The antiserum bound $38 \%$ of ${ }^{125} \mathrm{I}$-labelled progesterone and binding was significantly $(P<0 \cdot 0 \mathrm{I}$, Student's $t$ test) reduced by the addition of $0.8 \mathrm{pg}$ progesterone per tube. Addition of $8 \mathrm{pg}$ progesterone resulted in displacement of $50 \%$ of bound ${ }^{125}$ I-labelled progesterone. Cross-reactivities at the $50 \%$ displacement level were as follows: $11 \beta$-hydroxyprogesterone, $91.5 \% ; 11 \alpha$-hydroxyprogesterone, $82.7 \% ; 5 \alpha$-pregnanedione, $46.5 \%$; $5 \beta$-prenanedione, $11.3 \% ; 17 \alpha$-hydroxyprogesterone, $8.7 \%$; corticosterone, $1.1 \%, 16 \alpha$-hydroxyprogesterone, $1 \%$; oestradiol, androstenedione, 5 $\beta$-pregnanediol, $5 \alpha$-pregnanediol and testosterone, $<0.9 \% ; 20 \alpha$-dihydroprogesterone and cortisol, $<0.2 \%$. To examine whether the assay measured plasma steroids other than progesterone, extracts of plasma $(n=4)$ to which trace amounts of $\left[{ }^{3} \mathrm{H}\right]$ progesterone had been added were processed by Celite column chromatography (Abraham et al., 1973): 93\% of progesterone as determined by radioimmunoassay eluted in the same fractions as the peak of tritiated progesterone. When hormone concentration in 7 plasma samples was measured with and without celite chromatography of the plasma extract, the relationship between estimates was described by the equation $y=0.91 x+56.9(r=0.99)$.

Plasma extracts inhibited binding of ${ }^{125} \mathrm{I}$-labelled progesterone in a dose-related manner which paralleled that of progesterone standard. To assess the accuracy of the assay, authentic progesterone was added to plasma samples containing low progesterone concentration. Recovery of progesterone which was added at $100,200,400$ and $800 \mathrm{pg} / \mathrm{ml}$ was $73 \pm 8,72 \pm 2,79 \pm 3$ and $93 \pm 2 \%$ (s.e.m.; $n=4$ ) respectively. The intra-assay coefficient of variation, assessed by repeated assay in duplicate of two pools of plasma containing 188 and 708 pg progesterone/mi, was 4.8 and $6.7 \%$ respectively $(n=10)$. The inter-assay coefficient of variation, determined from repeated measurement of the progesterone concentration in 2 pools of plasma containing 276 and $581 \mathrm{pg} / \mathrm{ml}$, was 16 and $12.4 \%$ respectively $(n=15)$. The progesterone concentration measured in buffer or charcoal stripped plasma was below the level of sensitivity of the standard curve $(20 \mathrm{pg} / \mathrm{ml})$.

All results are expressed as the mean \pm s.e.m.

\section{Experiment 1}

\section{Results}

After removal of pouch young from 8,6 and 11 females on 16 February 1984 and 14 and 25 January 1985 , births occurred to 1,3 and 1 females respectively.

\section{Experiment 2}

Pouch young were removed at a time of year when all animals should respond by terminating quiescence. The results indicate that all animals showed evidence of a reproductive cycle. For each animal, the total number of cells and the proportion of cornified cells in the vaginal smear increased markedly over the period from Day 23 to 30 . Furthermore all animals showed a significant $(P<0.05$, Day $2 v s$ Day 3; paired $t$ test) increase in progesterone concentration (Fig. 1)) by Day 3 and a transient peak on Day $4(\mathrm{~N}=6)$ or Day $5(\mathrm{~N}=2)$ which was followed several days later by increased progesterone concentrations which remained elevated until Day 28. Five animals gave birth $27 \pm 0.2$ days after removal of pouch young and these plus 1 other animal were mated, each showing a mating plug and a coloured mating mark. From these results it was decided that twice weekly blood samples for progesterone determination would provide a clear distinction between animals in quiescence and animals in the luteal phase of a pregnant or non-pregnant cycle. Concentrations of progesterone exceeding $300 \mathrm{pg} / \mathrm{ml}$ were considered indicative of an active corpus luteum. The coloured marking technique appeared to be a reliable indicator of mating with the advantage that the mark on the females was visible for several days.

\section{Experiment 3}

The onset of seasonal quiescence was studied using the techniques developed above. The results in Fig. 2 indicate that no animals showed evidence of seasonal quiescence, i.e. failure to show high 


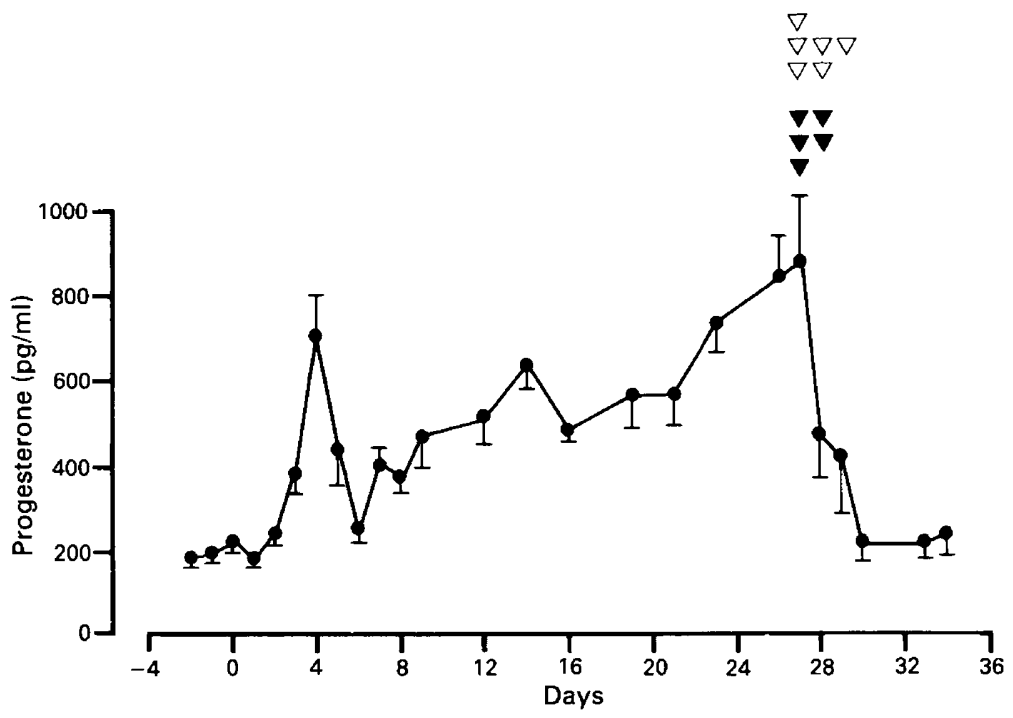

Fig. 1. Plasma progesterone concentrations (mean \pm s.e.m.) in 8 Bennett's wallabies after pouch young were removed (Day 0 ) during lactational diapause, $\mathbf{\nabla}$, birth; $\nabla$, mating.

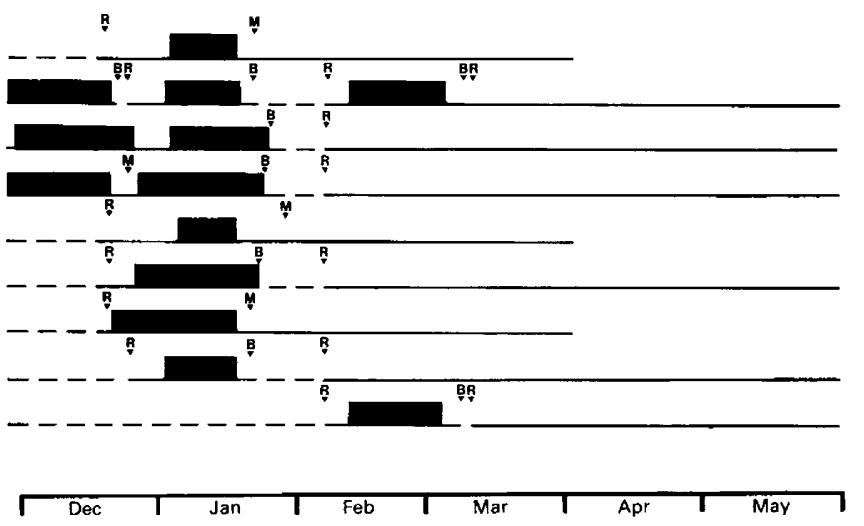

Fig. 2. Reproductive cycles in female Bennett's wallaby during the transition from lactational to seasonal diapause. Broken lines $(---)$ indicate periods of lactation, solid lines $(-)$ periods when progesterone concentrations were $<300 \mathrm{pg} / \mathrm{ml}$, and blocks periods when progesterone concentrations were $>300 \mathrm{pg} / \mathrm{ml}$. R, removal of pouch young; B, birth; M, mating.

progesterone concentrations after removal of pouch young or oestrus, until 23 January. Between 23 January and 5 February, 7 animals were in seasonal quiescence. The 2 remaining animals first showed evidence of seasonal quiescence after removal of pouch young on $6 \mathrm{March}$.

\section{Discussion}

In the present study the peripheral progesterone profile of delayed reproductive cycles followed a pattern similar to that previously reported for this species (Walker \& Gemmell, 1983) and different from that of the tammar wallaby in that the transient progesterone peak occurred 4-5 rather than 5-7 days after removal of pouch young (Hinds \& Tyndale-Biscoe, 1982). The progesterone concentrations measured here in Bennett's wallaby exceed those reported for the same species by Walker 
\& Gemmell (1983) by nearly 2-fold but are similar to those measured in the tammar by other authors (Hinds \& Tyndale-Biscoe, 1982; Shaw \& Renfree, 1984). Although the assay used in the present study cross-reacted with some steroids, the experiments with Celite chromatography suggest that progesterone is the major plasma steroid measured in this assay.

In many marsupials mating can be detected by observation of a mating plug. For accurate results daily capture and close examination of the female is necessary as the mating plug may be visible for less than $24 \mathrm{~h}$ after copulation. The coloured wax marking technique used in the present study proved to be a reliable and potentially useful method for detecting mating, particularly since the coloured mark on mated females was visible for at least 3 days after mating and could be observed without the need to catch and restrain the females. Therefore this technique alone could be used to follow reproduction with the advantage that there would be minimal disruption to the animals under study.

Although there have been few studies of the transition from lactational to seasonal quiescence in either the Bennett's or the tammar wallaby, it has been generally accepted that the transition occurs at about the winter solstice. In the present study all animals continued to show reproductive cycles after removal of pouch young between 17 and 25 December. The onset of seasonal quiescence occurred during the 10 weeks after the winter solstice so that, by $6 \mathrm{March}$, all animals were in seasonal quiescence. These findings differ from those of Merchant \& Calaby (1981) who removed pouch young from several females around the time of the winter solstice and found that 1 animal entered seasonal quiescence as early as 4 weeks before the winter solstice and that all animals were in seasonal quiescence after the week following the winter solstice. Nevertheless, Merchant \& Calaby (1981) recorded that 1 of a total of 44 births occurred in early August indicating that this 1 animal was not in seasonal quiescence about $1-2$ weeks after the winter solstice. In a number of studies of the tammar wallaby, pouch young have been removed 1 or 2 months after the winter solstice and based on the absence of births 1 month later, it appears that all animals were in seasonal quiescence (Sadleir \& Tyndale-Biscoe, 1977; Renfree et al., 1981; Hinds \& den Ottolander, 1983; Tyndale-Biscoe \& Hinds, 1984). At present it is not possible to account for the differences between studies but it is possible that the timing of the transition from lactational to seasonal quiescence may vary with species, climatic and nutritional conditions in successive years, or perhaps in different populations or at different latitudes.

The annual change in photoperiod is a major factor controlling the seasonal reproductive cycle of the tammar (Sadleir \& Tyndale-Biscoe, 1977; Hinds \& den Ottolander, 1983) and Bennett's wallabies (J. D. Curlewis \& A. S. I. Loudon, unpublished results). In the tammar, the role of photoperiod in termination of seasonal quiescence and the physiological mechanisms involved in this process have been studied extensively (McConnell \& Tyndale-Biscoe, 1985; McConnell et al., 1986). In contrast, there have been no studies on the role of photoperiod in the initiation of seasonal quiescence. Renfree et al. (1981) have shown that removal of the superior cervical ganglion from the tammar wallaby during the period of decreasing daylength prevents the normal onset of seasonal quiescence. This suggests that the tammar requires either prolonged exposure to short days or increasing daylength after the winter solstice before animals will enter seasonal quiescence. In several species of eutherian mammal a change in reproductive status after the winter solstice occurs independently of increasing daylength; that is, animals become refractory to the prevailing photoperiod with termination of the breeding season in sheep (Robinson \& Karsch, 1984) and initiation of the breeding season in hamsters (for a review, see Reiter, 1980). In both the tammar and the Bennett's wallaby, the role of photoperiod in the initiation of seasonal quiescence remains to be determined.

We thank Ms A. Coleman and Ms S. Williams for assistance with the collection of samples; Ms A. Beasy for catching wallabies at Whipsnade Park; and Dr J. Foulkes, Cattle Breeding Centre, M.A.F.F., Shinfield, Reading, for the gift of antiserum. This study was supported by a grant from the S.E.R.C. of the U.K. 


\section{References}

Abraham, G.E., Buster, J.E., Kyle, F.W., Corrales, P.C. \& Teller, R.C. (1973) Radioimmunoassay of plasma pregnenolone. J. clin. Endocr. Metab. 37, 40-45.

Andrewartha, H.G. \& Barker, S. (1969) Introduction to a study of the ecology of the Kangaroo Island wallaby, Protemnodon eugenii (Desmarest) within Flinders Chase, Kangaroo Island, South Australia. Trans. Roy. Soc. S. Aust. 93, 127-133.

Berger, P.J. (1966) Eleven-month 'embryonic diapause' in a marsupial. Nature Lond. 211, 435-436.

Berger, P.J. \& Sharman, G.B. (1969) Embryonic diapause initiated without the suckling stimulus in the wallaby, Macropus eugenii. J. Mammal. 50, 630-632.

Catt, D.C. (1977) The breeding biology of Bennett's wallaby (Macropus rufogriseus fructicus) in South Canterbury, New Zealand. N.Z. J. Zool. 4, 401-411.

Curlewis, J.D., White, A.S., Loudon, A.S.I. \& McNeilly, A.S. (1986) Effects of lactation and season on plasma prolactin concentrations and response to bromocriptine during lactation in the Bennett's wallaby (Macropus rufogriseus rufogriseus). J. Endocr. 110, 59-66.

Fleming, D., Cinderey, R.N. \& Hearn, J.P. (1983) The reproductive biology of Bennett's wallaby (Macropus rufogriseus rufogriseus) ranging free at Whipsnade Park. J. Zool., Lond. 201, 283-291.

Hinds, L.A. \& den Ottolander, R.C. (1983) Effect of changing photoperiod on peripheral plasma prolactin and progesterone concentrations in the tammar wallaby (Macropus eugenii). J. Reprod. Fert. 69, 631-639.

Hinds, L.A. \& Tyndale-Biscoe, C.H. (1982) Plasma progesterone levels in the pregnant and non-pregnant tammar, Macropus eugenii. J. Endocr. 93, 99-107.

McConnell, S.J. \& Tyndale-Biscoe, C.H. (1985) Response in peripheral plasma melatonin to photoperiod change and the effects of exogenous melatonin on seasonal quiescence in the tammar wallaby, Macropus eugenii. J. Reprod. Fert. 73, 529-538.

McConnell, S.J., Tyndale-Biscoe, C.H. \& Hinds, L.A. (1986) Change in duration of elevated concentrations of melatonin is the major factor in photoperiod response of the tammar, Macropus eugenii. J. Reprod. Fert. 77, 623-632.
Merchant, J.C. (1979) The effect of pregnancy on the interval between one oestrus and the next in the tammar wallaby (Macropus engenii). J. Reprod. Fert. 56, $459-463$.

Merchant, J.C. \& Calaby, J.H. (1981) Reproductive biology of the Red-necked wallaby (Macropus rufogriseus banksianus) and Bennett's wallaby (M. $r$. rufogriseus) in captivity. J. Zool., Lond. 194, 203-217.

Reiter, R.J. (1980) The pineal and its hormones in the control of reproduction in mammals. Endocrine Review's 1, 109-131.

Renfree, M.B., Lincoln, D.W., Almeida, O.F.X. \& Short, R.V. (1981) Abolition of seasonal embryonic diapause in a wallaby by pineal denervation. Nature, Lond. 293, 138-139.

Robinson, J.E. \& Karsch, F.J. (1984) Refractoriness to inductive daylengths terminates the breeding season of the Suffolk ewe. Biol. Reprod. 31, 656-663.

Sadleir, R.M.F. \& Tyndale-Biscoe, C.H. (1977) Photoperiod and the termination of embryonic diapause in the marsupial Macropus eugenii. Biol. Reprod. 16, $605-608$.

Shaw, G. \& Renfree, M.B. (1984) Concentrations of oestradiol- $17 \beta$ in plasma and corpora lutea throughout pregnancy in the tammar, Macropus eugenii. $J$. Reprod. Fert. 72, 29-37.

Tyndale-Biscoe, C.H. \& Hinds, L.A. (1984) Seasonal patterns of circulating progesterone and prolactin and the response to bromocriptine in the female tammar Macropus eugenii. Gen. comp. Endocr. 53, 58-68.

Tyndale-Biscoe, C.H., Hearn, J.P. \& Renfree, M.B. (1974) Control of reproduction in macropodid marsupials. J. Endocr. 63, 589-614.

Walker, M.T. \& Gemmell, R.T. (1983) Plasma concentrations of progesterone, oestradiol-17 $\beta$ and $13,14-$ dihydro-15-oxo-prostaglandin $\mathrm{F}_{2 \alpha}$ in the pregnant wallaby (Macropus rufogriseus rufogriseus). $J$. Endocr. 97, 369-377.

Webley, G.E. \& Edwards, R. (1985) Direct assay for progesterone in saliva: comparison with a direct serum assay. Ann. Clin. Biochem. 22, 579-585.

Received 1 August 1986 